\title{
EVIDENCIAÇÃO DE ATIVOS INTANGÍVEIS: ESTUDO EMPÍRICO EM COMPANHIAS ABERTAS
}

\author{
DISCLOSURE OF INTANGIBLE ASSETS: EMPIRICAL STUDY OF LISTED \\ COMPANIES
}

\section{Resumo}

Bruna Camargos Avelino ${ }^{a}$; Laura Edith Taboada Pinheiro ${ }^{b}$; Wagner Moura Lamounier ${ }^{c}$

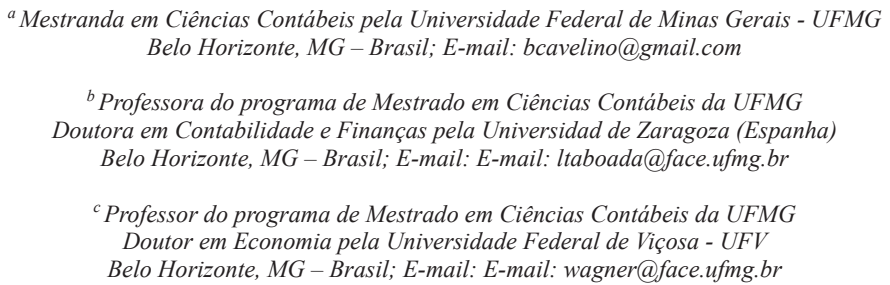

O objetivo do presente estudo consiste em apresentar um índice de evidenciação de informações compulsórias sobre ativos intangíveis de empresas listadas no Ibovespa, referente ao exercício de 2010, observando os critérios de reconhecimento, mensuração e registro destes ativos conforme especificações do CPC 04 (R1), além de verificar se existe relação entre o índice e o tamanho das empresas, o setor em que estas estão inseridas e a quantidade de anos de constituição das companhias. No que concerne ao índice de evidenciação, optou-se por construir um índice próprio, a partir dos dados estruturados na pesquisa de Moura et al. (2011), baseados nas especificações do CPC 04 (R1). Os resultados mostraram que a empresa COPEL apresentou o maior índice de evidenciação de ativos intangíveis (88\%), porém, nenhuma das companhias analisadas cumpriu integralmente o que é determinado pelo CPC 04 (R1) em termos de evidenciação compulsória. Além disso, constatou-se que existe relação entre os índices de evidenciação e a variável independente tamanho, relação esta não verificada quando se analisa os anos de constituição das empresas. Em relação ao setor de atuação, não se verificou, na amostra analisada, que empresas inseridas em setores sensíveis tendem a apresentar maiores índices de evidenciação.

Palavras-chave: Evidenciação; Ativos Intangíveis; CPC 04.

\begin{abstract}
This study aims to provide a disclosure index of disseminated informations about intangible assets of listed companies on São Paulo Stock Exchange Index (Ibovespa) referring to 2010, noting the criteria for recognition, measurement, and recording of these assets as specified by the CPC 04 (R1). Also it intends to verify if there is relationship between the index and companies' size, the sector in which they are inserted, and the longevity of companies' establishment. Regarding the disclosure index, it was decided to construct its own index, from the structured data of Moura et al. (2011) study, based on the CPC 04 (R1) specifications. The results showed that Companhia Paranaense de Energia (COPEL) presented the highest disclosure rate of intangible assets (88\%), but none of the analyzed companies complied fully with what is determined by $C P C 04$ (RI) referring to mandatory disclosure. Moreover, it was found that there is relationship between the disclosure rates and the independent variable size, a relationship not seen when we analyze the time of companies' establishment. In this sample, regarding the activity sector, it was not found that companies included in sensitive sectors tend to have higher disclosure rates.
\end{abstract}

Keywords: Disclosure; Intangible Assets; CPC 04. 


\section{INTRODUÇÃO}

O atual ambiente socioeconômico demonstra a necessidade de se questionar as formas mercantilistas de perceber as organizações. Variáveis como informação, conhecimento, ativos intangíveis e capital intelectual reforçam a importância de se repensar os instrumentos preconizados na gestão das organizações (COLAUTO et al., 2009).

A importância dos recursos intangíveis no Sistema Capitalista, mais especificamente na Era da Informação, tornou-se notória com o desenvolvimento de estudos científicos oriundos da década de 1980. Nesse cenário, os termos ativo intangível e capital intelectual vinham sendo muitas vezes utilizados como sinônimos, posicionamento este que nãoé o considerado no presente artigo, haja vista que com a convergência das normas brasileiras às normas internacionais e a consequente aprovação do $\mathrm{CPC}$ 04, acredita-se que tal simplificação não reflita a situação atual. O CPC 04 estabelece alguns critérios para que os recursos intangíveis sejam reconhecidos como ativos intangíveis, portanto, neste contexto, considera-se adequada a observação de Zanini e Calvo (2006) que salientam que o capital intelectual tem um conceito amplo, não exatamente delimitado na teoria da contabilidade, por ser tema estudado e de interesse conjunto das ciências empresariais e econômicas. Por outro lado, o ativo intangível tem um conceito muito mais restrito, uma vez que normalmente está baseado nas normas contábeis emanadas por organismos reguladores, embora o próprio desenvolvimento da teoria da contabilidade faça com que essas normas evoluam ao longo do tempo (ZANINI e CALVO, 2006).

Devido ao crescente aumento da materialidade dos valores dos ativos intangíveis no que diz respeito à composição do patrimônio líquido das empresas, tornou-se imprescindível verificar o tratamento dado internacionalmente a esse item tão complexo da contabilidade (SCHMIDT e SANTOS, 2003). Ressalta-se, nesse sentido, a importância de estudos sobre o tema, dentre os quais pode-se citar as pesquisas de Colauto et al. (2009), Macagnan (2009) e Moura et al. (2011). Colauto et. al, (2009) analisaram o conteúdo da evidenciação de recursos intangíveis não adquiridos nos Relatórios da Administração de companhias abertas brasileiras listadas nos níveis de governança corporativa, além de verificar se havia correlação entre as informações sobre tais intangíveis e o desempenho econômico das empresas.

Macagnan (2009) identificou os fatores que influenciavam na extensão da evidenciação voluntária de recursos intangíveis em empresas listadas no Mercado Contínuo da Bolsa de Valores da Espanha. Moura et al. (2011), por sua vez, verificaram se entre as maiores empresas brasileiras listadas nos diversos setores econômicos da BM\&FBovespa, aquelas com maior conformidade quanto ao disclosure obrigatório dos ativos intangíveis e com maior proporção de tais ativos em seu ativo fixo foram as que apresentaram melhores práticas de governança corporativa.

Assim, diante das novas exigências estabelecidas pelo Pronunciamento Técnico - CPC 04 (R1) - Ativo Intangível, elaborou-se a seguinte questão de pesquisa: como as empresas listadas na BM\&FBovespa evidenciaram os ativos intangíveis em suas demonstrações contábeis no ano de 2010? Para responder à questão da pesquisa, o estudo tem como objetivo geral apresentar um índice de evidenciação de informações compulsórias sobre ativos intangíveis de empresas listadas na carteira teórica do Ibovespa em 2011, observando os critérios de reconhecimento, mensuração e registro destes ativos conforme especificações do CPC 04 (R1). O índice supracitado foi elaborado com base nos estudos de Moura et al. (2011), sendo baseado nas especificações do CPC 04 (R1). Porém, adicionalmente à análise do índice, o 
estudo pretende verificar se a extensão da evidenciação obrigatória dos ativos intangíveis está associada ao tamanho das empresas, ao setor em que estas estão inseridas e à quantidade de anos de constituição das companhias. Como contribuição, este estudo pretende averiguar se o comportamento das empresas no que se refere às políticas de evidenciação de ativos intangíveis está condizente com o que determina a legislação, de forma que tais companhias possam usufruir dos benefícios advindos da ampla divulgação de informações, conforme elencados pela literatura, além de fornecer subsídios para os usuários na tomada de decisões.

Adicionalmente, a pesquisa visa prover elementos para entender se há associação entre a evidenciação compulsória de ativos intangíveis e determinadas características das empresas analisadas. Desse modo, este estudo pretende, além de apresentar um índice de evidenciação de informações compulsórias sobre ativos intangíveis, ajudar a identificar determinadas características das empresas que poderiam ser consideradas como fatores explicativos para a extensão da evidenciação concernente a esses ativos.

$\mathrm{O}$ artigo está estruturado em cinco seções, iniciando-se com esta introdução. Na sequência, faz-se uma incursão teórica no que se refere às conceituações de Ativo Intangível e Capital Intelectual, além de tratar da Evidenciação de Ativos Intangíveis. Em seguida, aborda-se o método e procedimentos do estudo realizado. Após, apresentam-se os resultados da pesquisa empírica; e por fim, os comentários conclusivos sobre os achados.

\section{PLATAFORMA TEÓRICA}

\subsection{Capital intelectual e ativo intangível: aspectos conceituais}

Zanini e Calvo (2006) salientam que os termos ativo intangível e capital intelectual são muitas vezes utilizados como sinônimos, o que, efetivamente, não representa um erro, haja vista que dentro de um determinado contexto é possível utilizá-los como conceitos equivalentes. No entanto, os autores supracitados reforçam que é perfeitamente possível diferenciar seus conceitos mais centrais, uma vez que capital intelectual é um conceito mais geral e ativo intangível muito mais restrito.

As primeiras tentativas de definir ou explicar o capital intelectual relacionavam o termo, de forma geral, à capacidade intelectual humana. Atualmente, adicionaram-se ao conhecimento humano variáveis como marcas, patentes, designs, lideranças, lealdade de clientes, tecnologia de informação, treinamento de funcionários, indicadores de qualidade, relacionamento com fornecedores, desenvolvimento de novos produtos e outros fatores (COLAUTO; MAMBRINI, 2006). Edvinsson e Sullivan (1996) definem capital intelectual como o conhecimento que pode ser convertido em lucros para a empresa e que se encontra formado por recursos como as idéias, designs, programas de computador, processos de dados, etc. Não é limitado a inovações tecnológicas ou àquelas formas de propriedade intelectual identificadas pela lei (patentes, segredos industriais).

Para Stewart (1998, p. XIII) "o capital intelectual constitui a matéria intelectual conhecimento, informação, propriedade intelectual, experiência - que pode ser utilizada para gerar riqueza. É a capacidade mental coletiva. É difícil identificá-lo e mais difícil ainda distribuí-lo de forma eficaz". Edvinsson e Malone (1998) dividem o capital intelectual em 
capital humano e capital estrutural, de modo que o primeiro engloba o conhecimento, expertise, poder de inovação e habilidade dos empregados mais os valores, a cultura e a filosofia da empresa, enquanto o segundo é formado pelos equipamentos de informática, softwares, banco de dados, patentes, marcas registradas, relacionamento com clientes e tudo o mais da capacidade organizacional que apóia a produtividade dos empregados. Os autores ressaltam ainda que o relacionamento com clientes pode ser desdobrado em um grupo à parte como capital de clientes, dando maior ênfase a este item para o valor da empresa.

Verifica-se, a partir destas definições, que o capital intelectual possui um conceito amplo, sendo tema de interesse conjunto das ciências empresariais e econômicas. Já o termo ativo intangível, possui um conceito muito mais restrito, uma vez que está normalmente embasado nas normas contábeis emanadas por organismos reguladores (ZANINI; CALVO, 2006). Uma definição restritiva pode ser encontrada em Recio (2005, apud ZANINI; CALVO, 2006): o ativo intangível representa os elementos do capital intelectual que são suscetíveis de reconhecimento como ativo, de acordo com as normas de contabilidade, isto é, as inversões que podem ser reconhecidas como ativos e serem refletidas no balanço patrimonial da empresa. Nessa mesma linha, o CPC 04 (R1) estabelece que para se enquadrarem na definição de ativo intangível, os itens devem ser identificáveis, controlados e geradores de benefícios econômicos futuros.

Iudícibus et al. (2010) e Hendriksen e Van Breda (1999) salientam que a definição de intangível precisa conter, obrigatoriamente, além do fator intangibilidade, os mesmos conceitos da definição de ativo, quais sejam: (a) recurso controlado pela entidade como resultado de eventos passados; e (b) do qual se espera que resultem benefícios econômicos futuros para a entidade (CPC 04, 2010). Os autores acrescentam ainda que ativos que carecem de substância devem ser reconhecidos sempre que preencherem os requisitos de reconhecimento de todo e qualquer ativo, ou seja, devem atender à definição de ativo, devem ser mensuráveis e devem ser relevantes e precisos.

As entidades frequentemente despendem recursos ou contraem obrigações com a aquisição, o desenvolvimento, a manutenção ou o aprimoramento de recursos intangíveis como conhecimento científico ou técnico, projeto e implantação de novos processos ou sistemas, licenças, propriedade intelectual, conhecimento mercadológico, nome, reputação, imagem e marcas registradas. Exemplos de itens que se enquadram nessas categorias amplas são: softwares, patentes, direitos autorais, direitos sobre filmes cinematográficos, listas de clientes, direitos sobre hipotecas, licenças de pesca, quotas de importação, franquias, relacionamentos com clientes ou fornecedores, fidelidade de clientes, participação no mercado e direitos de comercialização (CPC 04, 2010).

Todos esses itens se enquadram na definição de capital intelectual, mas nem todos, conforme ressalta o CPC 04 (R1), se enquadram na definição de ativo intangível, ou seja, são identificáveis, controlados e geradores de benefícios econômicos futuros. De forma similar, Clacher (2010) coloca que alguns intangíveis, tais como competências de pessoal, relacionamento com clientes, eficácia de sistemas gerenciais e conhecimento de mercado, normalmente não são reportados nos relatórios contábeis por não estarem de acordo com os requisitos de identificação, controle e garantia de benefício econômico futuro. Estes recursos intangíveis se enquadram na definição ampla de capital intelectual, porém, por não serem passíveis de reconhecimento no balanço patrimonial, não são considerados ativos intangíveis, conforme posicionamento deste artigo.

Portanto, neste estudo, optou-se por manter a menção de Zanini e Calvo (2006) de que os termos capital intelectual e ativo intangível não são sinônimos, de modo que, na presente 
pesquisa, utiliza-se a denominação ativo intangível apenas para itens identificáveis, controlados e geradores de benefícios econômicos futuros e que, consequentemente, são passíveis de reconhecimento no balanço patrimonial da empresa.

Em relação ao reconhecimento dos ativos intangíveis, o CPC 04 (R1) prevê que para um item ser reconhecido pela contabilidade como ativo intangível é necessário atender à definição de ativo e ainda:

(a) for provável que os benefícios econômicos futuros esperados atribuíveis ao ativo serão gerados em favor da entidade; e

(b) o custo do ativo possa ser mensurado com confiabilidade.

A entidade deve avaliar a probabilidade de geração de benefícios econômicos futuros utilizando premissas razoáveis e comprováveis que representem a melhor estimativa da administração em relação ao conjunto de condições econômicas que existirão durante a vida útil do ativo.

A entidade deve utilizar seu julgamento para avaliar o grau de certeza relacionado ao fluxo de benefícios econômicos futuros atribuíveis ao uso do ativo, com base nas evidências disponíveis no momento do reconhecimento inicial, dando maior peso às evidências externas.

De acordo com o CPC 04 (R1), um ativo intangível deve ser reconhecido inicialmente pelo custo. No que concerne à mensuração após reconhecimento, a norma estabelece que, quando a opção pelo método de reavaliação não estiver restringida por lei ou norma legal regularmente estabelecida, a entidade deve optar por reconhecer o ativo intangível pelo método de custo ou pelo método de reavaliação. No Brasil, a reavaliação não é permitida devido às disposições contidas na Lei $n^{\circ}$. 11.638/07, que alterou a Lei $n^{\circ}$. 6.404/76.

\subsection{Evidenciação de ativos intangíveis}

Para o entendimento da evidenciação (ou divulgação), vale reportar-se ao termo na língua inglesa, disclosure. Conforme esclarece Goulart (2003, p. 58), “o disclosure pode ser entendido como o oposto de fechamento, significando a 'abertura' da empresa por meio da divulgação de informações, garantindo a transparência corporativa diante do público e dos participantes de mercado". Portanto, neste estudo, os termos "evidenciação", "divulgação" e "disclosure" foram tratados como sinônimos.

Evidenciação, de acordo com Aquino e Santana (1992), refere-se à divulgação com clareza, divulgação em que se compreende de imediato o que está sendo comunicado. Vieira(2006) salienta que, com uma correta divulgação, os agentes interessados na empresa terão instrumentos para análise, acompanhamento e comparação do desempenho social da organização, além de sua situação econômica, financeira e patrimonial. Para Niyama e Gomes (1996) a evidenciação diz respeito à qualidade das informações de caráter financeiro e econômico sobre as operações, recursos e obrigações de uma entidade. Estas informações devem ser úteis aos usuários das demonstrações contábeis, de forma que influenciem na tomada de decisões, envolvendo a entidade e o acompanhamento da evolução patrimonial, possibilitando o conhecimento das ações passadas e a realização de inferências em relação ao futuro.

Para Hendriksen e Van Breda (1999), o disclosure pode ser classificado em três níveis: divulgação adequada, justa e completa. A divulgação adequada pressupõe um volume mínimo de divulgação compatível com o objetivo de evitar que as demonstrações sejam enganadoras. A divulgação justa subentende um objetivo ético de tratamento equitativo de todos os leitores 
em potencial e a divulgação completa implica na apresentação de toda a informação relevante. De acordo com Dobler (2005), um gestor que visa maximizar o valor de mercado da empresa vai optar pela divulgação completa, disponibilizando integralmente informações privadas, além daquelas consideradas obrigatórias, se é de conhecimento comum que o gestor está ciente daquele tipo de informação, se não existirem custos significativos associados ao disclosure e se as informações divulgadas puderem ser interpretadas da mesma forma por todos os usuários externos.

Nesse cenário, a evidenciação pode ser entendida como um elemento de transparência para a gestão das empresas, uma vez que a divulgação de informações é imprescindível para que os usuários externos conheçam a posição da entidade e se certifiquem de que esta opera dentro dos limites considerados aceitáveis pela legislação, reduzindo, inclusive, a possibilidade de irregularidades e fraudes.

Especificamente quando se trata da evidenciação de ativos intangíveis, as normas peculiares relacionadas a estes itens são estabelecidas no Pronunciamento Técnico CPC 04, revisado em 2010 (CPC 04 - R1), sendo apresentados no documento supracitado os critérios para reconhecimento, métodos de mensuração e divulgação desses ativos. Tais determinações são obrigatórias para empresas abertas, uma vez que o Pronunciamento em questão foi aprovado pela Deliberação CVM n ${ }^{\circ}$ 553/2008. O CPC 04 (R1) determina que os ativos intangíveis devam ser separados por classes, como por exemplo: marcas, títulos de periódicos, softwares, licenças e franquias, direitos autorais, receitas, fórmulas, projetos e intangíveis em desenvolvimento.

De acordo com o CPC 04 (R1), a empresa deve divulgar as seguintes informações para cada classe de ativos intangíveis, fazendo a distinção entre ativos intangíveis gerados internamente e outros ativos intangíveis:

a) se a vida útil do intangível é definida ou indefinida, justificando os motivos que fundamentam a avaliação e os fatores mais importantes que levaram à respectiva definição, além dos prazos de vida útil ou as taxas de amortização utilizadas;

b) o valor contábil bruto e eventual amortização acumulada (mais as perdas acumuladas no valor recuperável) no início e no final do período;

c) a rubrica da demonstração do resultado em que qualquer amortização de ativo intangível for incluída; e

d) a conciliação do valor contábil no início e no final do período, incluindo informações sobre adições, baixas e transferências, ativos classificados como mantidos para venda ou outras baixas, bem como os adquiridos por meio de combinação de negócios.

A entidade deve divulgar também informações sobre ativos intangíveis que perderam o seu valor de acordo com o Pronunciamento Técnico CPC 01 - Redução ao Valor Recuperável de Ativos, além do total de gastos com pesquisa e desenvolvimento reconhecidos como despesas no período (CPC 04, 2010).

Segundo Moura et al. (2011), até a aprovação do CPC 04 (R1), a evidenciação voluntária sobre os ativos intangíveis é que vinha exercendo o importante papel de possibilitar mais informações aos stakeholders. Desse modo, a promulgação do CPC 04 (R1) culminou na exigência de uma melhor evidenciação dos elementos intangíveis das empresas, uma vez que definiu critérios para reconhecimento, mensuração e exigências específicas sobre informações a serem divulgadas sobre este grupo de ativo. 
Nesta pesquisa, serão avaliadas apenas as evidenciações obrigatórias constantes no CPC 04 (R1), assim como foi realizado no estudo de Moura et al. (2011). Os autores supracitados verificaram se entre as maiores empresas brasileiras listadas nos diversos setores econômicos da BM\&FBovespa, aquelas com maior conformidade quanto ao disclosure obrigatório dos ativos intangíveis e com maior proporção de tais ativos em seu ativo fixo, foram as que apresentaram melhores práticas de governança corporativa. Para tal, consultaram dados do balanço patrimonial, notas explicativas, relatórios de administração e IANs disponíveis no site da BM\&FBovepa e websites de 49 companhias.

Moura et al. (2011) calcularam, primeiramente, o índice de tamanho dos intangíveis, caracterizado pelo percentual dos ativos intangíveis em relação ao ativo permanente total do ano de 2009. Depois, calcularam o índice de conformidade das informações divulgadas sobre ativos intangíveis e, na sequência, calcularam o índice de governança corporativa elaborado de acordo com o estudo de Silveira, Barros e Famá (2004). Por fim, os autores utilizaram, na análise estatística, o coeficiente de correlação de Pearson, e os resultados demonstraram que entre as maiores empresas brasileiras listadas nos diversos setores econômicos da BM\&FBovespa, aquelas com maior conformidade quanto ao disclosure obrigatório dos ativos intangíveis e com maior proporção de tais ativos em seu ativo fixo foram as que apresentaram melhores práticas de governança corporativa.

Vale salientar que se optou por não abordar a evidenciação voluntária de recursos intangíveis em decorrência de já existirem diversos estudos recentes sobre o tema, tais como as pesquisas de Rêgo et al. (2008), Colauto et al. (2009) e Macagnan (2009). Rêgo et al. (2008) verificaram se as empresas do segmento de papel e celulose, que possuíam ações negociadas na BOVESPA, estavam evidenciando seu capital intelectual. Para isso, os autores analisaram documentos relativos às notas explicativas e aos relatórios da administração das empresas que se enquadravam no segmento de papel e celulose, referentes ao ano de 2006. Dentre os resultados encontrados, Rêgo et al. (2008) verificaram que todas as empresas evidenciavam, de uma forma ou de outra, informações relativas ao capital intelectual, estando $16 \%$ delas apresentadas por meio de notas explicativas e a maioria, ou seja, 84\%, por meio dos relatórios da administração, destacando-se que as empresas de maior faturamento tendiam a evidenciar uma maior quantidade de informações relacionadas à formação do capital intelectual.

Colauto et al. (2009) analisaram o conteúdo da evidenciação de recursos intangíveis não adquiridos nos Relatórios da Administração de 80 companhias abertas brasileiras listadas nos níveis de governança corporativa, além de verificar se havia correlação entre as informações sobre tais intangíveis e o desempenho econômico das empresas. Os autores constataram que as empresas do Novo Mercado e do Nível 1 que possuíam maior valor de mercado, tendiam a evidenciar mais características intangíveis nos relatórios da administração. Já as empresas do Nível 2 que possuíam maior valor de mercado não evidenciavam, de forma expressiva, maior número de características referentes aos ativos intangíveis, o que poderia ser decorrente da semelhança entre as empresas quanto à posse de características intangíveis.

Macagnan (2009), por sua vez, identificou os fatores que influenciavam na extensão da evidenciação voluntária de recursos intangíveis em 94 empresas listadas no Mercado Contínuo da Bolsa de Valores da Espanha. Para o desenvolvimento da pesquisa, a autora utilizou dados obtidos no relatório anual, publicado na página da Internet, das empresas que compuseram a amostra. Os resultados apontaram que fatores como o tamanho, o setor, o endividamento, o grau de internacionalização, os anos de existência e a diferença entre o preço da ação sobre o valor contábil da empresa explicavam a maior extensão da evidenciação de informação de recursos intangíveis. Já fatores como a rentabilidade, o grau de monopólio e o capital flutuante da companhia, explicavam a menor extensão da evidenciação dessas informações. 


\section{PROCEDIMENTOS METODOLÓGICOS}

O estudo, de caráter descritivo, utilizou a pesquisa documental e análise multivariada de dados. A população do estudo foi composta pelas 63 empresas listadas na carteira teórica do Ibovespa para o quadrimestre de maio a agosto de 2011. Optou-se, porém, por não incluir na análise empresas que atuam no mercado financeiro, como bancos, seguradoras e caixas econômicas, devido às suas particularidades. Portanto, a amostra deste estudo foi composta, inicialmente, por 53 empresas listadas no Ibovespa que não se configuram como instituições financeiras. Dentre estas 53 empresas, seis foram excluídas da análise, por motivos distintos, a saber: três companhias não apresentaram a rubrica de Ativos Intangíveis em seus Balanços Patrimoniais, tornando inviável a construção de um índice de evidenciação específico para este item; as outras três apresentaram problemas concernentes à vida útil de seus ativos intangíveis, tornando inviável, para as companhias em questão, a construção de um índice de evidenciação de ativos intangíveis que trata da amortização e vida útil desses ativos em diversos itens. Portanto, a amostra final do estudo foi composta por 47 empresas listadas na carteira teórica do Ibovespa. Os procedimentos metodológicos, incluindo a justificativa para a seleção das empresas, encontram-se detalhados a seguir.

O Índice Bovespa é o mais importante indicador do desempenho médio das cotações do mercado de ações brasileiro. Sua relevância advém do fato deste índice retratar o comportamento dos principais papéis negociados na BM\&FBovespa e também de sua tradição, haja vista que o Ibovespa manteve a integridade de sua série histórica e não sofreu modificações metodológicas desde sua implementação em 1968 (BM\&FBOVESPA, 2012). Desse modo, justifica-se a escolha de empresas listadas no referido índice como população de pesquisa em decorrência deste servir como indicador médio do comportamento do mercado, além do fato de que as ações integrantes da carteira teórica do índice supracitado respondem por mais de $80 \%$ do número de negócios e do volume financeiro verificados no mercado a vista da BM\&FBovespa (BM\&FBOVESPA, 2008), assim, as empresas que englobam a carteira teórica do Ibovespa podem ser consideradas representativas do mercado de capitais como um todo.

Dentre o universo das 63 empresas listadas na carteira teórica do Ibovespa para o quadrimestre de maio a agosto de 2011, o setor de construção e transporte é o mais representado, com 12 empresas (19\% do total), seguido pelo setor de materiais básicos, com 10 empresas (16\%), pelos setores de consumo não cíclico e utilidade pública, cada um com 9 empresas (14\%), setor de telecomunicações, com 6 empresas (10\%), setores de consumo cíclico e petróleo, gás e combustível, cada um com 3 empresas $(5 \%)$ e setor de bens industriais, com uma empresa (1\%). Conforme já mencionado, não se encontram incluídas na amostra as empresas que atuam no mercado financeiro. Tais empresas compõem $16 \%$ do total das 63 entidades listadas na carteira teórica do Ibovespa, de modo que representam a diferença entre o número de empresas a princípio analisadas no estudo (53) e o total das empresas listadas.

Os dados coletados para a construção do índice de evidenciação de informações compulsórias sobre ativos intangíveis foram retirados dos Balanços Patrimoniais das entidades selecionadas, tomando como base os relatórios referentes ao exercício de 2010 e respectivas notas explicativas, divulgados no site da BM\&FBovespa. Segundo Alencar (2007), os pesquisadores têm se dividido entre construir o próprio indicador de disclosure ou trabalhar com rankings já existentes. Desse modo, optou-se por construir um índice a partir dos dados estruturados na pesquisa de Moura et al. (2011), baseados nas especificações do CPC 04 (R1). O índice é composto por 17 quesitos, conforme demonstrado no Quadro 1. 


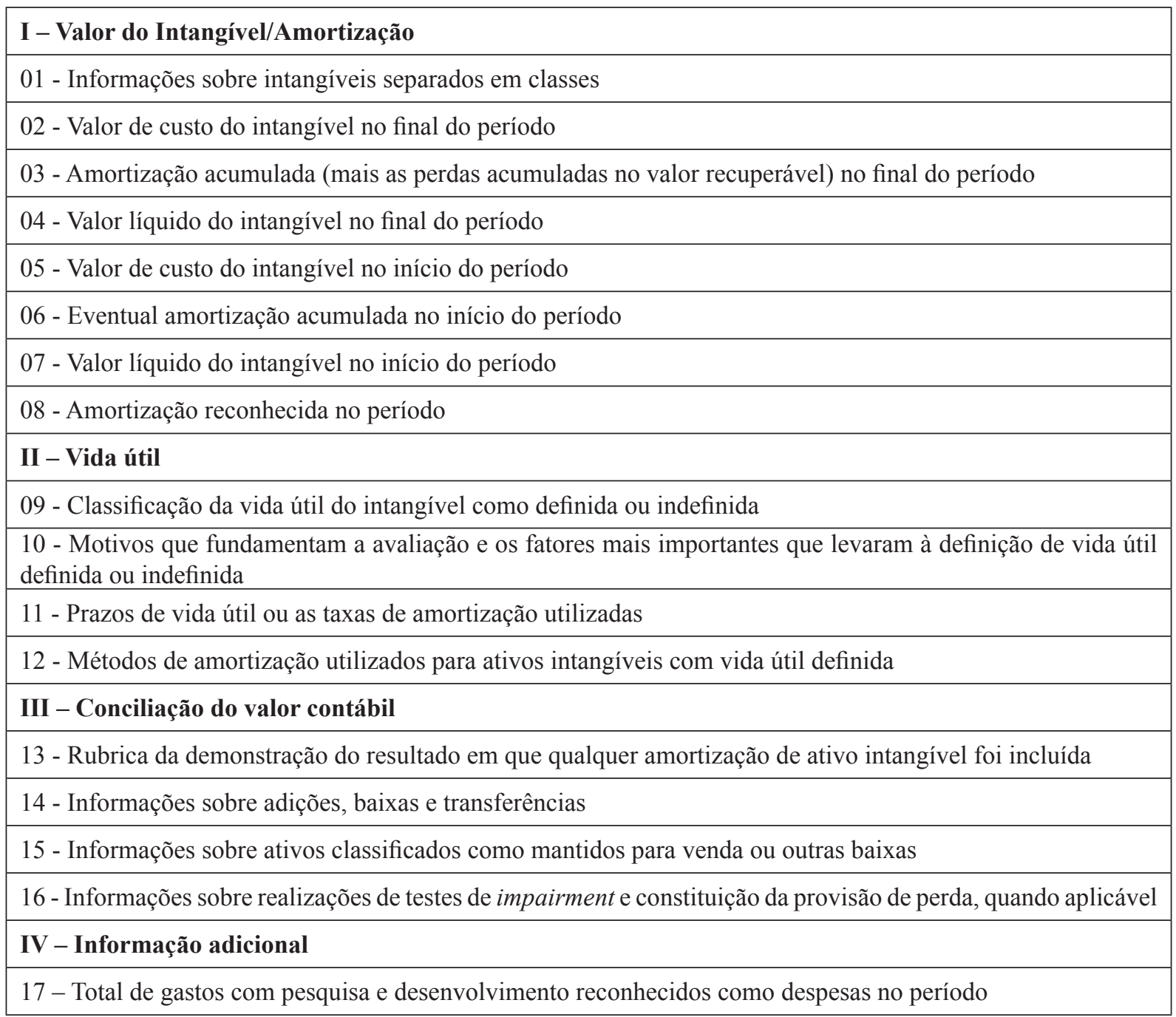

Quadro 1: Informações a serem divulgadas.

Fonte: Adaptado de Moura et al. (2011) e do CPC 04 (2010).

Assim como realizado na pesquisa de Moura et al. (2011), para cada resposta poderiam ser atribuídas três notas $(0,1$ ou 2$)$, sendo 0 no caso da não divulgação da informação pela entidade; nota 1 , caso a empresa disponibilizasse a informação na demonstração contábil e respectivas notas explicativas; e 2 quando a questão não era aplicável para determinadas empresas. Moura et al. (2011) salientam que se o índice fosse composto apenas por questões binárias (0 e 1), a empresa poderia ser penalizada por não revelar um tipo específico de informação que não se aplica à sua realidade operacional. Optou-se por seguir a metodologia aplicada nos estudos de Gordon et al. (2002) e Lima (2009) quanto a índices de disclosure, de forma que não foi atribuído qualquer tipo de pontuação para a quantidade ou qualidade da evidenciação, haja vista não haver informações disponíveis para realizar este tipo de avaliação. Portanto, limitou-se à verificação da divulgação ou não da informação, quando esta era aplicável.

Ao final da coleta, as empresas que receberam, em alguma das questões, pontuação 2 (considerada não aplicável), foram removidas da análise, de modo a não comprometer o resultado final. Assim, empresas que não apresentaram a rubrica de Ativos Intangíveis no Balanço Patrimonial; ou que apresentaram nesta conta apenas ativos intangíveis com vida útil indefinida, portanto, não passíveis de amortização; ou ainda aquelas companhias que declararam que a amortização dos intangíveis não foi iniciada ou não se aplica ao exercício analisado, foram excluídas da análise.

Nesse sentido, foram eliminadas da amostra as empresas GERDAU, GERDAU MET e 
CESP, por não apresentarem nos Balanços Patrimoniais a rubrica de ativos intangíveis. Também foram excluídas da análise as empresas PDG, OGX PETRÓLEO e CTEEP. Em relação à primeira, nota-se que a rubrica de ativos intangíveis evidenciada pela empresa é composta pelo ágio, que não é amortizado por ter vida útil indefinida, sendo a recuperação do seu valor testada anualmente, e por ativos classificados como software e outros intangíveis. Estes últimos correspondem basicamente à aquisição e custos de implantação do novo software operacional da companhia, cuja previsão de início de amortização será a partir de janeiro de 2011, denotando a não aplicabilidade (pontuação 2) de questões que remetam à amortização de intangíveis.

A OGX informou que os ativos registrados no grupo de intangíveis terão sua vida útil definida apenas quando as controladas OGX Ltda. e OGX Maranhão estiverem em sua fase de produção e serão amortizados pelo método das unidades a serem produzidas em relação às reservas totais a serem aprovadas. Consequentemente, a amortização ainda não foi iniciada em função do estágio da atividade pré-operacional, inferindo-se que questões relacionadas à amortização de intangíveis não se aplicam à empresa em questão (pontuação 2).

Por fim, tem-se que o montante de ativos intangíveis da CTEEP é representado, basicamente, pelos gastos incorridos na implantação do ERP, sendo que os efeitos de amortização decorrentes da primeira análise periódica do prazo de vida útil e econômica remanescente dos bens do ativo intangível, conforme determinado pelo ICPC 10, não foram considerados relevantes pela administração da companhia. Tal situação denota a não aplicabilidade (pontuação 2) da divulgação de algumas das informações elencadas no Quadro 1, principalmente as que fazem menção à amortização dos ativos intangíveis.

Desta maneira, o índice compreende somente a soma das questões que receberam pontuação 0 e 1, dividida pela pontuação total possível do conjunto de informações (17 quesitos), sendo a amostra final da pesquisa composta por 47 empresas.

\subsection{Hipóteses}

Estudos sobre disclosure têm identificado uma série de benefícios oriundos da divulgação de informações por uma empresa, tais como redução dos custos de agência e do custo de capital, melhoria na liquidez de ações, além de outros benefícios não tão facilmente captáveis. Quanto mais informações uma empresa divulga, mais os investidores são capazes de avaliar, de forma eficaz, o quão bem a direção da empresa está explorando as oportunidades disponíveis (GUTTENTAG, 2004). Diante desse cenário, os pesquisadores têm demonstrado interesse em estudar as práticas de evidenciação das empresas e os fatores que influenciam tais práticas (HOPE, 2003).

Com o intuito de atingir os objetivos específicos propostos e verificar se há associação entre evidenciação de ativos intangíveis conforme o CPC 04 (R1), aprovado pela Deliberação $\mathrm{CVM} \mathrm{n}^{\circ} 553 / 2008$ e características da entidade, foram testadas na pesquisa três hipóteses, já analisadas no estudo de Macagnan (2009) em relação à extensão da evidenciação voluntária de recursos intangíveis:

- $\quad \mathrm{H}_{1}$ : Existe uma relação positiva entre o tamanho da entidade e a extensão da evidenciação obrigatória dos ativos intangíveis da empresa conforme o CPC 04.

De acordo com Ahmed e Courtis (1999), diversos pesquisadores da área de contabilidade têm investigado a associação entre características corporativas e a divulgação de informações nos relatórios anuais corporativos desde 1961. Os resultados destes estudos têm demonstrado consistentemente que o tamanho das empresas tem sido significativamente associado aos níveis 
de divulgação. Nessa mesma linha, Macagnan (2009) afirma que o tamanho da empresa é uma das causas mais comuns nos estudos que objetivam explicar a extensão da evidenciação de informações. São as grandes empresas que têm maior número de contratos, projetos, atividades produtivas e comerciais e que necessitam de mais financiamento; realidade que gera mais demanda informativa (MACAGNAN, 2009). Quanto maior for a empresa, maior será a pressão dos grupos políticos no sentido de transferir riquezas para a sociedade, de modo que a evidenciação pode ser um meio de impedir a intervenção política e reguladora do Estado, além de ajudar a influenciar a visibilidade política da empresa, visando assegurar contratos com órgãos governamentais (WATTS e ZIMMERMAN, 1990). De acordo com Nunes, Teixeira e Nossa (2009), o tamanho das empresas é mensurado normalmente nos trabalhos pelo número de empregados, valor do ativo total, receita de vendas ou de acordo com ranking de periódicos. Nesta pesquisa, optou-se por utilizar o logaritmo natural $(l n)$ do ativo total de cada empresa como proxy para representar o tamanho, sendo os valores correspondentes à rubrica supracitada coletados por meio do banco de dados Economática ${ }^{\circledR}$.

- $\quad \mathrm{H}_{2}$ : Empresas inseridas em setores considerados sensíveis apresentam uma relação positiva com a extensão da evidenciação obrigatória dos ativos intangíveis conforme o CPC 04.

Segundo Cooke (1991), há pouca probabilidade de que os níveis de evidenciação no relatório anual sejam os mesmos em todos os setores da economia. Macagnan (2009) acrescenta que a realidade econômica das empresas pode configurar-se de forma diferenciada conforme o setor em que atuam, seja por suas diferenças de necessidade financeira, por sua imagem pública ou pelo custo de tributação, por exemplo.

Para Watts e Zimmerman (1978), empresas inseridas em setores sensíveis, tais como indústria farmacêutica, setor de serviços públicos, setor florestal e a indústria de petróleo e gás, estão sujeitas a custos políticos potencialmente elevados, em especial aos relacionados à evidenciação de ganhos elevados. Os autores salientam que esses custos políticos são decorrentes de aspectos contratuais e de lobbies, e provenientes da regulação do Estado para as atividades da firma. De acordo com Beuren e Söthe (2008), organizações com custos políticos potencialmente elevados, embora não seja uma prerrogativa exclusivamente destas, quando se sentem ameaçadas em sua legitimidade, necessitam e procuram ampliar as evidenciações compulsórias e voluntárias, recuperando ou diminuindo a possibilidade de perda de legitimidade.

No presente estudo, a hipótese setor é representada por uma variável dummy que engloba empresas inseridas em setores considerados sensíveis, aqui representados por setores baseados na classificação da BM\&FBovespa: Consumo não Cíclico, quando se relaciona a empresas do segmento de cigarros e fumo; Materiais básicos, quando se refere a empresas petroquímicas ou do setor florestal (madeireiras, de papel e celulose, e siderúrgicas que utilizam carvão vegetal); Petróleo, Gás e Biocombustíveis; e Utilidade Pública. Assim, a segunda hipótese visa verificar se o setor ao qual a entidade pertence poderia explicar a extensão da evidenciação de seus ativos intangíveis, de modo a corroborar ou não a premissa de que empresas inseridas em setores sensíveis tendem a divulgar maior quantidade de informações com vistas a conquistar, manter ou recuperar sua legitimidade.

- $\quad \mathrm{H}_{3}$ : Existe uma relação negativa entre a quantidade de anos de constituição da entidade e a extensão da evidenciação obrigatória dos ativos intangíveis da empresa conforme o CPC 04.

Gallardo e Castilla (2004) citados por Macagnan (2009) afirmam que os anos de constituição de uma empresa são identificados como uma causa explicativa da extensão da evidenciação. Desse modo, conforme Macagnan (2009), as empresas jovens são mais caracterizadas pela incerteza do que as com mais tempo de existência, por isso pressupõe-se que estas precisariam prestar mais informações. A autora acrescenta que enquanto a empresa 
com mais tempo de existência poderia representar solidez, a empresa com poucos anos poderia significar maior risco e uma nova oportunidade de ganhos acima da média de mercado, de forma que as novas empresas necessitariam fornecer informações a fim de estabelecer maior confiança sobre o investimento para o acionista. Neste estudo, a hipótese anos de constituição é constituída pela variável que calcula o tempo de formação da empresa, obtido mediante consulta às páginas eletrônicas das entidades, até o ano de 2010.

Portanto, foram definidas, para fins desta pesquisa, as seguintes variáveis: tamanho, setor de atuação e anos de constituição da empresa como variáveis explicativas; e índice de evidenciação de informações compulsórias sobre ativos intangíveis, em relação às especificações do CPC 04, como variável dependente. A técnica estatística utilizada para identificar a associação entre a variável dependente e as variáveis independentes foi a análise de regressão múltipla, conforme modelo que segue:

onde:

IND.INTANG = índice de evidenciação de informações compulsórias sobre ativos intangíveis, conforme especificações do CPC 04

$\ln$ Ativo Total $=$ proxy para representar o tamanho

Ano $=$ Anos de constituição da empresa

$\mathbf{D}_{\mathbf{3}}=\mathbf{1}$, se a empresa pertence a algum dos setores sensíveis elencados no estudo e $=0$, nos demais casos

O processamento dos dados estatísticos foi realizado por meio do software STATA ${ }^{\circledR}$. Ressalta-se que foram realizados testes para a verificação dos principais problemas relacionados aos pressupostos do modelo clássico de regressão linear, quais sejam: multicolineariedade, heterocedasticidade e correta especificação da forma funcional.

\subsection{Limitações da pesquisa}

Quanto às limitações da pesquisa, salienta-se que as conclusões obtidas ficaram restritas à amostra, uma vez que esta foi intencional e não probabilística, impossibilitando generalizações. Ademais, uma parcela das empresas inicialmente selecionadas não puderam compor a amostra final do estudo, em decorrência dos motivos explicitados na metodologia, ocasionando uma diminuição da amostra em análise, o que prejudica ainda mais possíveis generalizações. A terceira limitação refere-se ao fato de que o nível de disclosure elaborado não é um fim em si mesmo, haja vista que está restrito às informações elencadas pelo CPC 04 (R1), podendo ser aumentado adicionando-se informações divulgadas a título de evidenciação voluntária. Nesse sentido, como não foi estabelecida uma ponderação acerca da relevância das informações concernentes aos ativos intangíveis, corre-se o risco de, ao restringir-se à evidenciação compulsória, serem excluídas outras informações que também possam ser relevantes.

Além dessas questões, partindo-se dos pressupostos adotados no estudo de que existe uma relação positiva entre o tamanho da entidade e a extensão da evidenciação obrigatória dos ativos intangíveis, de que empresas inseridas em setores considerados sensíveis apresentam uma relação positiva com o nível de disclosure e de que empresas mais jovens tenderiam a prestar mais informações, foram construídas relações de causalidade entre as variáveis. Porém, conforme ressalta Cruz (2010), a causalidade é objeto de considerável discussão dentro da filosofia da ciência. Nesse contexto, Hume (2004) entende que a questão de dois fenômenos estarem associados quanto à sua ocorrência não quer dizer que há uma dependência entre si, 
assim, assume-se que o fato de um estudo adotar um princípio que de certa forma é bastante questionado representa uma limitação para o mesmo (CRUZ, 2010).

\section{ANÁLISE DOS RESULTADOS \\ 4.1 Evidenciação dos ativos intangíveis}

$\mathrm{Na}$ Tabela 1 apresenta-se o resumo das evidenciações de cada item pesquisado, detalhando-se a quantidade de empresas que divulgaram as informações concernentes a cada um dos componentes do check list, bem como a porcentagem equivalente.

Tabela 1: Resumo das evidenciações por grupo (I, II, III e IV)

\begin{tabular}{|c|c|c|c|}
\hline Item de Evidenciação & Total & Evidenciação & Percentual \\
\hline \multicolumn{4}{|l|}{ I - Valor do Intangível/Amortização } \\
\hline 01 - Informações sobre intangíveis separados em classes & 47 & 46 & $97,87 \%$ \\
\hline 02 - Valor de custo do intangível no final do período & 47 & 47 & $100,00 \%$ \\
\hline $\begin{array}{l}03 \text { - Amortização acumulada (mais as perdas acumuladas no valor } \\
\text { recuperável) no final do período }\end{array}$ & 47 & 41 & $87,23 \%$ \\
\hline 04 - Valor líquido do intangível no final do período & 47 & 41 & $87,23 \%$ \\
\hline 05 - Valor de custo do intangível no início do período & 47 & 47 & $100,00 \%$ \\
\hline 06 - Eventual amortização acumulada no início do período & 47 & 39 & $82,98 \%$ \\
\hline 07 - Valor líquido do intangível no início do período & 47 & 40 & $85,11 \%$ \\
\hline 08 - Amortização reconhecida no período & 47 & 41 & $87,23 \%$ \\
\hline \multicolumn{4}{|l|}{ II - Vida útil } \\
\hline $\begin{array}{l}09 \text { - Classificação da vida útil do intangível como definida ou } \\
\text { indefinida }\end{array}$ & 47 & 39 & $82,98 \%$ \\
\hline $\begin{array}{l}10 \text { - Motivos que fundamentam a avaliação e os fatores mais } \\
\text { importantes que levaram à definição de vida útil definida ou } \\
\text { indefinida }\end{array}$ & 47 & 3 & $6,38 \%$ \\
\hline 11 - Prazos de vida útil ou as taxas de amortização utilizadas & 47 & 38 & $80,85 \%$ \\
\hline $\begin{array}{l}12 \text { - Métodos de amortização utilizados para ativos intangíveis com } \\
\text { vida útil definida }\end{array}$ & 47 & 38 & $80,85 \%$ \\
\hline \multicolumn{4}{|l|}{ III - Conciliação do valor contábil } \\
\hline $\begin{array}{l}13 \text { - Rubrica da demonstração do resultado em que qualquer } \\
\text { amortização de ativo intangível foi incluída }\end{array}$ & 47 & 6 & $12,77 \%$ \\
\hline 14 - Informações sobre adições, baixas e transferências & 47 & 37 & $78,72 \%$ \\
\hline $\begin{array}{l}15 \text { - Informações sobre ativos classificados como mantidos para } \\
\text { venda ou outras baixas }\end{array}$ & 47 & 1 & $2,13 \%$ \\
\hline $\begin{array}{l}16 \text { - Informações sobre realizações de testes de impairment e } \\
\text { constituição da provisão para perda, quando aplicável }\end{array}$ & 47 & 47 & $100,00 \%$ \\
\hline \multicolumn{4}{|l|}{ IV - Informação adicional } \\
\hline $\begin{array}{l}17 \text { - Total de gastos com pesquisa e desenvolvimento reconhecidos } \\
\text { como despesas no período }\end{array}$ & 47 & 10 & $21,28 \%$ \\
\hline
\end{tabular}

Fonte: elaborado pelos autores.

Observa-se, a partir da análise da Tabela 1, que os itens 02 (valor de custo do intangível no final do período), 05 (valor de custo do intangível no início do período) e 16 (informações sobre realizações de testes de impairment) foram divulgados pela totalidade das empresas analisadas. Em relação aos itens 02 e 05 , todas as companhias mencionaram que os ativos intangíveis são 
avaliados ao custo de aquisição, deduzido da amortização acumulada e perdas por redução do valor recuperável, quando aplicável. Enfatizaram ainda que os intangíveis adquiridos em uma combinação de negócios e reconhecidos separadamente do ágio são registrados contabilmente pelo valor justo na data de aquisição e, em um momento subsequente, são registrados ao valor de custo, deduzido da amortização e da perda por redução ao valor recuperável acumuladas. As entidades apresentaram dados comparativos de 2009 e 2010, atendendo aos itens 02 e 05 elencados na Tabela 1.

No que concerne ao item 16, todas as empresas pesquisadas informaram que o ágio e os ativos intangíveis com vida útil indefinida têm a recuperação do seu valor testada anualmente, independentemente de haver indicadores de perda de valor. Quanto aos ativos que estão sujeitos à amortização, as companhias mencionaram que estes são revisados para a verificação de impairment sempre que eventos ou mudanças nas circunstâncias indicarem que o valor contábil pode não ser recuperável. Conforme o CPC 01 (Redução ao Valor Recuperável de Ativos) se o valor recuperável de um ativo, que se refere ao maior montante entre o seu valor justo líquido de despesa de venda e o seu valor em uso, for inferior ao seu valor contábil, o valor contábil do ativo deve ser reduzido ao seu valor recuperável. Essa redução representa uma perda por desvalorização do ativo. Nesse sentido, apesar de todas as companhias mencionarem a realização de testes de impairment, somente as empresas USIMINAS, PETROBRÁS, TELEMAR N L, TELEMAR e ELETROBRÁS registraram provisões para perda estimada por redução ao valor recuperável. As demais companhias informaram que não foram identificadas quaisquer evidências que justificassem a necessidade de redução ao valor recuperável dos ativos intangíveis em 2010.

Informações sobre intangíveis separados em classes (item 1) foram divulgadas por 46 das 47 companhias analisadas. A empresa KLABIN apresentou a rubrica de ativos intangíveis somente de forma sintética no Balanço Patrimonial, não especificando nas notas explicativas as classes de ativos que são escrituradas.

As informações menos divulgadas foram as relacionadas aos itens 10 (motivos que fundamentam a avaliação da vida útil do ativo em definida ou indefinida) e 15 (informações sobre ativos classificados como mantidos para venda ou outras baixas). No que se refere ao primeiro item, somente as empresas COPEL, GOL e NATURA detalharam alguns dos fatores considerados para a classificação da vida útil dos ativos intangíveis em definida ou indefinida.

A COPEL enfatizou que a amortização do intangível reflete o padrão em que se espera que os benefícios econômicos futuros do ativo sejam consumidos pela empresa, com expectativa de amortização média de $15 \%$ ao ano, limitados ao prazo da concessão. A GOL informou que a vida útil estimada dos direitos de operação foi considerada indefinida devido a diversos fatores e considerações, incluindo requerimentos e autorizações de permissão para operar no Brasil e limitada disponibilidade de slots nos mais importantes aeroportos em termos de volume de tráfego. Em relação às marcas, a empresa salientou que a vida útil estimada destas foi considerada indefinida devido a diversos fatores e considerações, incluindo o conhecimento da marca e sua posição no mercado, e o reconhecimento e fidelização dos clientes no uso contínuo das marcas da VARIG. Por fim, a NATURA mencionou que as taxas de amortização utilizadas pela empresa consideram os prazos de aluguel dos imóveis arrendados, os quais variam de três a cinco anos. As demais entidades somente divulgaram as taxas de amortização às quais os ativos intangíveis estão submetidos e/ou o prazo de vida útil em anos, sem maiores detalhamentos.

Informações sobre ativos classificados como mantidos para venda ou outras baixas (item 15) somente foram detalhadas pela SABESP, de modo que a companhia evidenciou, além do montante de bens dos ativos intangíveis de concessão baixados no exercício de 2010, os motivos para este procedimento, tais como obsolescência, furtos, alienação e obras desativadas, 
poços improdutivos e projetos economicamente inviáveis.

Na Tabela 2 apresentam-se os índices de evidenciação de ativos intangíveis de cada uma das empresas pesquisadas.

Tabela 2: Índices de evidenciação de ativos intangíveis.

\begin{tabular}{l|l|r}
\hline \multicolumn{2}{c}{ Empresa } & Índice \\
\hline $\mathbf{1}$ & COPEL & $\mathbf{0 , 8 8}$ \\
\hline 2 & GOL & 0,82 \\
\hline 3 & MRV & 0,82 \\
\hline 4 & BRASKEM & 0,82 \\
\hline 5 & SID NACIONAL & 0,82 \\
\hline 6 & FIBRIA & 0,82 \\
\hline 7 & USIMINAS & 0,82 \\
\hline 8 & PETROBRAS & 0,82 \\
\hline 9 & CEMIG & 0,82 \\
\hline 10 & ELETROPAULO & 0,82 \\
\hline 11 & SABESP & 0,82 \\
\hline 12 & CCR SA & 0,76 \\
\hline 13 & CYRELA & 0,76 \\
\hline 14 & TAM S.A & 0,76 \\
\hline 15 & B2W VAREJO & 0,76 \\
\hline 16 & LOJAS AMERIC & 0,76 \\
\hline
\end{tabular}

\begin{tabular}{l|l|r}
\hline \multicolumn{2}{c}{ Empresa } & Índice \\
\hline 17 & RENNER & 0,76 \\
\hline 18 & AMBEV & 0,76 \\
\hline 19 & BRF FOODS & 0,76 \\
\hline 20 & SOUZA CRUZ & 0,76 \\
\hline 21 & P. AÇUCAR & 0,76 \\
\hline 22 & DURATEX & 0,76 \\
\hline 23 & BRASIL TEL. & 0,76 \\
\hline 24 & TIM & 0,76 \\
\hline 25 & TELESP & 0,76 \\
\hline 26 & TELEMAR N L & 0,76 \\
\hline 27 & TELEMAR & 0,76 \\
\hline 28 & CPFL ENERGIA & 0,76 \\
\hline 29 & ROSSI RESID & 0,71 \\
\hline 30 & HYPERMARCAS & 0,71 \\
\hline 31 & MARFRIG & 0,71 \\
\hline 32 & NATURA & 0,71 \\
\hline
\end{tabular}

\begin{tabular}{l|l|r}
\hline \multicolumn{1}{c}{ Empresa } & \multicolumn{1}{c}{ Índice } \\
\hline 33 & VALE & 0,71 \\
\hline 34 & VIVO & 0,71 \\
\hline 35 & LIGHT S/A & 0,71 \\
\hline 36 & ALL & 0,65 \\
\hline 37 & EMBRAER & 0,65 \\
\hline 38 & COSAN & 0,65 \\
\hline 39 & JBS & 0,65 \\
\hline 40 & ELETROBRAS & 0,65 \\
\hline 41 & MMX MINER & 0,59 \\
\hline 42 & GAFISA & 0,41 \\
\hline 43 & ECODIESEL & 0,41 \\
\hline 44 & BROOKFIELD & 0,35 \\
\hline 45 & LLX LOG & 0,35 \\
\hline 46 & PORTX & 0,35 \\
\hline 47 & KLABIN SA & 0,24 \\
\hline & & \\
\hline
\end{tabular}

Fonte: elaborado pelos autores.

Constatou-se que a empresa COPEL apresentou o maior índice de evidenciação de ativos intangíveis (88\%). Nas demonstrações contábeis da empresa supracitada, há destaque para a disponibilização de informações concernentes a alguns dos fatores mais importantes que levaram à definição da vida útil definida ou indefinida dos ativos intangíveis, informação evidenciada nas demonstrações contábeis de apenas 3 das 47 empresas pesquisadas (COPEL, GOL e NATURA); além da disponibilização do total de gastos com pesquisa e desenvolvimento reconhecidos como despesas no período, informação encontrada nas demonstrações contábeis de somente 10 das 47 empresas analisadas (COPEL, BRASKEM, SID. NACIONAL, PETROBRÁS, CEMIG, ELETROPAULO, SOUZA CRUZ, NATURA, VALE e LIGHT).

Na Tabela 3 apresenta-se a média dos índices de evidenciação de ativos intangíveis correspondentes a cada um dos quatro conjuntos de informações analisados.

Tabela 3: Índice de evidenciação por grupo.

\begin{tabular}{c|c}
\hline Grupos de Evidenciação & Média do índice \\
\hline I - Valor do Intangível/Amortização & $\mathbf{0 , 9 1}$ \\
\hline II - Vida útil & 0,63 \\
\hline III - Conciliação do valor contábil & 0,48 \\
\hline IV - Informação adicional & 0,21 \\
\hline
\end{tabular}

Fonte: elaborado pelos autores.

O grupo que apresentou maior índice foi o I com 91\%, de modo que quase a totalidade 
das empresas analisadas divulgaram informações relativas ao valor do ativo intangível e/ou das amortizações em seus demonstrativos contábeis. As informações mais evidenciadas neste grupo consistiram em informação sobre o valor de custo do intangível no final do período (divulgada pela totalidade das empresas) e sobre o valor de custo do intangível no início do período (evidenciada pela totalidade das companhias), além da apresentação dos intangíveis separados em classes (informação evidenciada por 46 empresas).

O segundo grupo a apresentar maior índice de evidenciação foi o grupo II, com 63\%. Em relação ao grupo II, a informação mais divulgada consistiu na classificação da vida útil do intangível como definida ou indefinida (disponibilizada nos demonstrativos contábeis de 39 entidades). No que se refere ao grupo III, a pesquisa revelou que as informações mais divulgadas foram as relativas a adições, baixas e transferências de ativos intangíveis, disponibilizadas nas demonstrações contábeis de 37 companhias. Por fim, verificou-se que o grupo IV, representado por informações relacionadas ao total de gastos com pesquisa e desenvolvimento reconhecidos como despesas no período, apresentou o menor índice de evidenciação, embora tais informações sejam de natureza obrigatória para as companhias abertas, conforme a Deliberação CVM n ${ }^{\circ}$ 553/2008 que aprovou as determinações do CPC 04 (Ativo Intangível). De modo geral, notase que as empresas mencionaram gastos com pesquisa e desenvolvimento nos Relatórios da Administração, mas a maioria destas não disponibilizou em seus demonstrativos contábeis o montante efetivamente reconhecido como despesa.

\subsection{Modelo de regressão}

Conforme já mencionado, foram estabelecidas no estudo as seguintes variáveis: índice de evidenciação de informações compulsórias sobre ativos intangíveis, em relação às especificações do CPC 04, como variável dependente; e tamanho, setor de atuação e anos de constituição da empresa como variáveis explicativas. Na Tabela 4, apresenta-se o resumo do modelo de regressão estimado inicialmente para analisar a evidenciação obrigatória de ativos intangíveis pelas companhias pesquisadas.

Tabela 4: Resumo do modelo de regressão inicialmente estimado.

\begin{tabular}{c|c|c|c|c}
\cline { 3 - 4 } & & & $\boldsymbol{R}^{2}$ & 0,2621 \\
\cline { 3 - 5 } & \multicolumn{3}{c}{$\boldsymbol{R}^{2}$ Ajustado } & 0,2106 \\
\cline { 3 - 5 } IND. INTANG & Coeficientes & Erro Padrão & $t$ & valor- $p$ \\
\hline InAtivoTotal & $\mathbf{0 , 0 3 8 1 6 6 6}$ & $\mathbf{0 , 0 1 0 4 7 6 7}$ & $\mathbf{3 , 6 4}$ & $\mathbf{0 , 0 0 1}$ \\
\hline Ano & $-0,0006847$ & 0,0006002 & $-1,14$ & 0,260 \\
\hline $\mathrm{D}_{3}$ & 0,02555 & 0,0455961 & 0,56 & 0,578 \\
\hline Constante & 0,0959107 & 0,1703637 & 0,56 & 0,576 \\
\hline
\end{tabular}

Fonte: elaborado pelos autores com base em dados do STATA ${ }^{\circledR}$.

A validação dos pressupostos do modelo clássico de regressão linear foi efetuada por meio da aplicação de testes quanto à homocedasticidade, ausência de multicolineariedade e correta especificação do modelo. Vale salientar que não foram realizados testes com vistas a verificar se os resíduos apresentavam autocorrelação, uma vez que trabalhou-se com dados de corte transversal, sendo, porém, este cuidado indispensável em dados de séries temporais, recomendando- 
se a realização do teste de Breusch-Godfrey. Para verificar a ausência de multicolineariedade, foram geradas regressões auxiliares e analisados os fatores de inflação da variância (Variance Inflating Factor - VIF) das variáveis explicativas. Segundo Gujarati (2006), quanto maior o VIF de uma variável $\mathrm{X}_{\mathrm{j}} \mathrm{em}$ um modelo, mais "problemática" ou colinear será aquela variável. Como os VIF encontrados foram baixos (menores que 10) não detectou-se relação linear entre as variáveis explicativas do modelo, conforme observado na Tabela 5.

Tabela 5: VIF das variáveis explicativas.

\begin{tabular}{l|l|l}
\hline \multicolumn{1}{c|}{ Variável } & VIF & \multicolumn{1}{c}{$\mathbf{1 / V I F}$} \\
\hline $\mathrm{D}_{3}$ & 1,27 & 0,790092 \\
\hline Ano & 1,22 & 0,822009 \\
\hline lnAtivoTotal & 1,06 & 0,945822 \\
\hline Média VIF & $\mathbf{1 , 1 8}$ \\
\hline
\end{tabular}

Fonte: Dados do STATA $®$.

Para verificar o problema da ausência de homocedasticidade (heterocedasticidade), realizou-se o teste de Breusch-Pagan. Segundo este teste, se a estatística Multiplicador de Lagrange (LM) for significativa ao nível de significância adotado (valor-p $<\alpha$ ), rejeita-se a hipótese nula de Homocedasticidade. Observando-se a Tabela 6, nota-se que o valor-p $(0,0023)$ é menor que o nível de significância adotado $(\alpha=0,05)$, denotando a rejeição da hipótese de que os resíduos do modelo possuem variância constante.

Tabela 6: Teste de Breusch-Pagan.

\begin{tabular}{l|c}
\hline chi2(3) & 14,51 \\
\hline Prob $>$ chi2 & 0,0023 \\
\hline
\end{tabular}

Fonte: Dados do STATA ${ }^{\circledR}$.

Optou-se então por re-estimar o modelo com erros-padrão robustos, como pode ser observado na Tabela 7.

Tabela 7: Resumo do modelo de regressão com erros-padrão robustos.

\begin{tabular}{|c|c|c|c|c|}
\hline & \\
\hline & & $R^{2}$ & 0,2621 & $\boldsymbol{R}^{2}$ \\
\hline IND. INTANG & Coeficientes & Erro Padrão & $t$ & valor-p \\
\hline InAtivoTotal & 0,0381666 & 0,0071999 & 5,30 & 0,000 \\
\hline Ano & $-0,0006847$ & 0,0008441 & $-0,81$ & 0,422 \\
\hline $\mathrm{D}_{3}$ & 0,02555 & 0,0514843 & 0,50 & 0,622 \\
\hline Constante & 0,0959107 & 0,1246945 & 0,77 & 0,446 \\
\hline
\end{tabular}

Finalmente, para verificar a correta especificação do modelo estimado, foi realizado o teste RESET. De acordo com este teste, desenvolvido por Ramsey (1969), supõe-se que, se o modelo correto for dado, nenhuma função não linear das variáveis explicativas deveria ser estatisticamente significativa quando adicionada a esse modelo. Desse modo, se o valor-p da estatística $\mathrm{F}$ for inferior ao nível de significância adotado $(\alpha=0,05)$ tem-se evidência estatística de que a forma funcional não foi corretamente especificada ou que variáveis relevantes foram omitidas no modelo.

Conforme observado na Tabela 8 , o resultado da estatística $\mathrm{F}$ foi menor que o nível de significância adotado $(\alpha=0,05)$, inferindo-se que há evidência estatística de que variáveis relevantes foram omitidas no modelo em análise, de modo que se recomenda a inclusão de 
novas variáveis explicativas em estudos futuros.

Tabela 8: Teste Ramsey RESET.

\begin{tabular}{l|c}
\hline F $(6,37)$ & 2,64 \\
\hline Prob $>$ F & 0,0313 \\
\hline
\end{tabular}

Fonte: Dados do STATA®.

Os resultados da estimação do modelo com erros-padrão robustos, evidenciados na Tabela 7, mostra uma variável estatisticamente significativa que explica a extensão da evidenciação obrigatória de ativos intangíveis, com um coeficiente $\mathrm{R}^{2}$ de 26,21\%. De acordo com a análise do valor-p, rejeita-se a hipótese nula de que o â $\hat{1}_{1}$, relacionado à variável $\ln$ AtivoTotal, seja estatisticamente igual a zero (valor-p menor que o $\alpha=0,05$ ), de forma que a hipótese sobre tamanho não pode ser rejeitada como uma causa explicativa da extensão da evidenciação obrigatória de ativos intangíveis. Esse resultado permite inferir que empresas maiores tendem a apresentar maiores níveis de evidenciação, corroborando estudos como os de Macagnan (2009) e Braga, Oliveira e Salotti (2009).

Macagnan (2009) encontrou evidências empíricas de que a variável tamanho (representada por duas variáveis: valor total das vendas e valor da capitalização) exerce influência direta e significativa sobre o nível de divulgação voluntária de recursos intangíveis, resultado similar ao encontrado por Braga, Oliveira e Salotti (2009). Estes últimos analisaram a extensão da divulgação ambiental e representaram a variável tamanho em função do logaritmo natural do ativo total ajustado.

Ao analisar-se a variável anos de constituição da companhia, não há evidências estatísticas para rejeitar a hipótese nula de que o $\beta_{2}$, relacionado à variável em questão, seja estatisticamente igual a zero (valor-p maior que o $\alpha=0,05$ ), de modo que a hipótese sobre anos de constituição da companhia pode ser rejeitada como uma causa explicativa da extensão da evidenciação obrigatória de ativos intangíveis. Tal resultado foi conflitante ao encontrado no estudo de Macagnan (2009) em relação à extensão da evidenciação voluntária de recursos intangíveis, uma vez que neste os anos de constituição da empresa revelaram-se variáveis explicativas estatisticamente significativas.

Vale ressaltar, no entanto, que a princípio a autora considerou como hipótese a existência de uma relação negativa entre a quantidade de anos de constituição da entidade e a extensão da evidenciação voluntária de recursos intangíveis, porém, os resultados demonstraram uma relação positiva, não confirmando o pressuposto de que as empresas com menos anos de existência evidenciam mais os recursos intangíveis que as mais antigas. Conforme já mencionado, no presente estudo não foi identificada relação de natureza positiva ou negativa.

No que concerne ao beta relacionado à variável $\mathrm{D}_{3}$, este foi considerado estatisticamente igual a zero (valor-p maior que o $\alpha=0,05$ ), denotando que não há diferenças entre as médias dos índices de evidenciação obrigatória de ativos intangíveis das empresas quando leva-se em consideração os setores a que estas pertencem. Portanto, no estudo em questão, não se verificou índices maiores de evidenciação em empresas pertencentes a setores considerados sensíveis.

Por fim, tem-se que o termo de intercepto também se revelou estatisticamente desprezível (estatisticamente igual a zero), indicando que, para todos os propósitos práticos, tem-se uma regressão que passa pela origem. 


\section{CONCLUSÕES}

Este estudo teve como objetivo apresentar um índice de evidenciação de informações compulsórias sobre ativos intangíveis de empresas listadas na carteira teórica do Ibovespa em 2011, observando os critérios de reconhecimento, mensuração e registro destes ativos conforme especificações do CPC 04 (R1), além de verificar se existe relação entre o índice e o tamanho das empresas, o setor em que estas estão inseridas e a quantidade de anos de constituição das companhias. Para tanto, a partir dos dados estruturados na pesquisa de Moura et al. (2011), baseados nas especificações do CPC 04 (R1), construiu-se um índice de evidenciação obrigatória de ativos intangíveis para as 47 empresas da amostra. Posteriormente, buscou-se identificar se havia relação entre o índice, utilizado como variável dependente, e as variáveis tamanho, setor e quantidade de anos de constituição das empresas, utilizadas como variáveis independentes.

O índice de evidenciação obrigatória de ativos intangíveis apresentado neste estudo possibilitou, além do conhecimento da realidade das empresas analisadas, obter uma visão de quais informações estas estão divulgando. Constatou-se que a empresa COPEL apresentou o maior índice de evidenciação de ativos intangíveis $(88 \%)$, porém, nenhuma das companhias analisadas cumpriu integralmente o que é determinado pelo CPC 04, aprovado pela Deliberação CVM n ${ }^{\circ} 553 / 2008$, em termos de evidenciação compulsória. Desse modo, aos resultados permitem inferir que a divulgação das informações geradas pela contabilidade de tais empresas não está plenamente adequada às exigências legais. Desse modo, se as empresas analisadas não cumprem sequer o que estabelece a legislação em termos de divulgação de informações compulsórias, estas, a princípio, poderiam deixar de valer-se dos benefícios apontados pela literatura como oriundos da maior divulgação de informações, tais como redução dos custos de agência e do custo de capital, melhoria na liquidez de ações, maximização do valor de mercado, dentre outros. Ademais, estão restringindo informações imprescindíveis para que investidores atuais e potenciais tomem decisões, haja vista que o aumento da evidenciação faz com que estes não tenham que confiar demasiadamente em sinais indiretos de criação de valor.

Porém, apesar dessa realidade, destaca-se que itens importantes de evidenciação já são frequentemente referenciados pelas companhias, tais como a divulgação de informações sobre as classes dos ativos intangíveis, o valor contábil e o valor amortizado destes, assim como a vida útil ou taxas de amortização dos ativos intangíveis. Em estudo realizado por Meneses, Ponte e Mapurunga (2011) nas demonstrações contábeis de 125 companhias listadas na BM\&FBovespa, referentes ao exercício de 2009, tal tendência já havia sido identificada.

Nota-se que o valor de custo do intangível no início e no final do período e as informações referentes a realizações de testes de impairment e constituição da provisão para perda foram divulgados pela totalidade das empresas analisadas, embora em relação a este último, somente as empresas USIMINAS, PETROBRÁS, TELEMAR N L, TELEMAR e ELETROBRÁS registraram provisões para perda estimada por redução ao valor recuperável. As demais companhias informaram que não foram identificadas quaisquer evidências que justificassem a necessidade de redução ao valor recuperável dos ativos intangíveis em 2010. As informações menos divulgadas foram as relacionadas aos motivos que fundamentam a avaliação da vida útil do ativo em definida ou indefinida, informação mencionada somente pelas empresas COPEL, GOL e NATURA e informações sobre ativos classificados como mantidos para venda ou outras baixas, divulgadas apenas pela SABESP.

No que se refere à verificação da existência ou não de associação entre as características tamanho da entidade, setor de atuação, quantidade de anos de constituição da empresa e o nível 
de evidenciação obrigatória dos ativos intangíveis, constatou-se, por meio dos resultados da aplicação do modelo de regressão múltipla, que existe relação entre os índices de evidenciação e a variável independente tamanho, representada pela proxy lnAtivoTotal, corroborando estudos anteriores que haviam constatado que empresas maiores tendem a divulgar uma maior quantidade de informações.

Em relação ao setor de atuação, não se verificou na amostra analisada que empresas inseridas em setores sensíveis tendem a apresentar maiores índices de evidenciação. Além disso, não se observou evidências estatísticas para confirmar a existência de relação entre os índices de evidenciação e a variável independente anos de constituição da empresa, resultado conflitante ao encontrado por Macagnan (2009).

Como sugestão para novos estudos, recomenda-se: acrescentar ao índice informações evidenciadas a título de divulgação voluntária, analisando, além das demonstrações contábeis e respectivas notas explicativas, os Relatórios da Administração; analisar a evolução das informações divulgadas sobre intangíveis, englobando as evidenciações realizadas nos dois exercícios anteriores ao considerado nesta pesquisa (2008 e 2009), uma vez que, apesar da revisão do CPC 04 se aplicar ao exercício de 2010, este foi editado e aprovado em 2008; e incluir novas variáveis independentes na análise, a fim de tentar corrigir a especificação do modelo.

\section{REFERÊNCIAS}

AHMED, K.; COURTIS, J. K. Associations between Corporate Characteristics and Disclosure Levels in Annual Reports: a Meta-Analysis. The British Accounting Review, v. 31, n. 1, p. 35-61, mar. 1999.

ALENCAR, R. C. de. Nível de disclosure e custo de capital próprio no mercado brasileiro. 2007. 114 f. Tese (Doutorado em Controladoria e Contabilidade) - Programa de Pós-Graduação em Controladoria e Contabilidade, Faculdade de Economia, Administração e Contabilidade da Universidade de São Paulo, São Paulo. Disponível em: <http://www.teses.usp.br/teses/ disponiveis/12/12136/tde-14032008-120509/pt-br.php>. Acesso em: 18 jul. 2011.

AQUINO, W. de; SANTANA, A. C. de. Evidenciação. Caderno de Estudos FIPECAFI, São Paulo, n. 5, p. 01-40, jun. 1992.

BEUREN, I. M.; SÖTHE, A. A teoria da legitimidade e o custo político nas evidenciações contábeis dos governos estaduais da região sudeste do Brasil. In: Congresso de Contabilidade e Auditoria, XII , 2008. Aveiro - Portugal. Anais... Aveiro - Portugal: ISCA, 2008. CD ROM.

BM\&FBOVESPA - Bolsa de Valores de São Paulo. Disponível em: <http://www.bmfbovespa. com.br/home.aspx?idioma=pt-br>. Acesso em: 09 mai. 2011.

Apresentação: Índice Bovespa - Ibovespa. Disponível em: <http://www. bmfbovespa.com.br/indices/ResumoIndice.aspx?Indice=IBOVESPA\&idioma=pt-br $>$. Acesso em: 5 abr. 2012.

Ibovespa: Definição e Metodologia, jan. 2008. Disponível em: < $\underline{\text { http://www. }}$ bmfbovespa.com.br/Pdf/Indices/IBovespa.pdf>. Acesso em: 5 abr. 2012. 
BRAGA, J. P.; OLIVEIRA, J. R. S.; SALOTTI, B. M. Determinantes do Nível de Divulgação Ambiental nas Demonstrações Contábeis de Empresas Brasileiras. In: Congresso USP de Controladoria e Contabilidade, $9^{\circ}$, 2009. São Paulo. Anais... São Paulo: USP, 2009. CD-ROM.

BRASIL. Lei $\mathrm{n}^{\mathrm{o}} 11.638$, de 28 de dezembro de 2007. Altera e revoga dispositivos da Lei no 6.404, de 15 de dezembro de 1976, e da Lei no 6.385, de 7 de dezembro de 1976, e estende às sociedades de grande porte disposições relativas à elaboração e divulgação de demonstrações financeiras. Disponível em: <http://www.planalto.gov.br/CCIVIL_03/_Ato2007-2010/2007/ Lei/L11638.htm>. Acesso em: 9 mai. 2011.

. Lei das Sociedades por Ações, Lei $n^{0}$ 6.404, de 15/12/1976. Dispõe sobre as sociedades por ações. Disponível em: <http://www.planalto.gov.br/ccivil_03/Leis/L6404consol. htm>. Acesso em: 23 mai. 2011.

CLACHER, I. National accounting for intangible assets in the knowledge economy. Journal of Financial Regulation and Compliance, v. 18, n. 2, p. 106-119, 2010.

COLAUTO et al. Evidenciação de Ativos Intangíveis Não Adquiridos nos Relatórios da Administração das Companhias Listadas nos Níveis de Governança Corporativa da Bovespa, Revista Contabilidade Vista \& Revista, v. 20, n. 1, p. 142-169, jan./mar. 2009.

COLAUTO. R. D.; MAMBRINI, A. Avaliação do Capital Intelectual não Adquirido: uma proposta para Instituição de Ensino Superior Privada. In: Congresso USP de Controladoria e Contabilidade, 6, 2006. São Paulo. Anais... São Paulo: USP, 2006. CD-ROM.

COOKE, T. E. Disclosure in the corporate annual reports of Swedish companies. Accounting and Business Research, v. 19, p. 113-124, 1991.

CPC - COMITÊ DE PRONUNCIAMENTOS CONTÁBEIS. Pronunciamento Técnico CPC 04 (R1): Ativo Intangível, 2010. Disponível em: <http://www.cpc.org.br/pdf/CPC04_R1.pdf $>$. Acesso em: 9 mai. 2011.

CPC - COMITÊ DE PRONUNCIAMENTOS CONTÁBEIS. Pronunciamento Técnico CPC 01 (R1): Redução ao Valor Recuperável de Ativos, 2010. Disponível em: <http://www.cpc.org.br/ pdf/CPC01R1.pdf>. Acesso em: 9 mai. 2011.

CRUZ, C. F. Transparência da Gestão Pública Municipal: Referenciais Teóricos e a Situação dos Grandes Municípios Brasileiros. 2010. 140 f. Dissertação (Mestrado em Ciências Contábeis) - Programa de Pós-Graduação em Ciências Contábeis, Faculdade de Administração e Ciências Contábeis da Universidade Federal do Rio de Janeiro, Rio de Janeiro.

CVM. Deliberação $n^{0} 553$, de 12 de Novembro de 2008. Aprova o Pronunciamento Técnico CPC 04 do Comitê de Pronunciamentos Contábeis, que trata de Ativos Intangíveis. Disponível em: < http://www.cvm.gov.br>. Acesso em: 9 mai. 2011.

DOBLER, M. How informative is risk reporting? A review of disclosure models. Munich Business Research Working Paper, Social Science Research Network, n. 1, jan. 2005. Disponível em: $<$ http://papers.ssrn.com/sol3/papers.cfm?abstract_id $=640522>$. Acesso em: 8 abr. 2012.

EDVINSSON, L.; MALONE, M. S. Capital Intelectual. São Paulo: Makron Books, 1998. 214 p.

EDVINSSON, L.; SULLIVAN, P. Developing a Model for Managing Intellectual Capital. 
European Management Journal, v. 14, n. 4, p. 356-364, ago. 1996.

GORDON, T. et al. A comparative empirical examination of extent of disclosure by private and public colleges and universities in the United States. Journal of Accounting and Public Policy, v. 21, n. 3, p. 235-275, 2002.

GOUlart, A. M. C. Evidenciação Contábil do Risco de Mercado por Instituições Financeiras no Brasil. 2003. 202 f. Dissertação (Mestrado em Ciências Contábeis) - Programa de Pós-Graduação em Controladoria e Contabilidade, Faculdade de Economia, Administração e Contabilidade da Universidade de São Paulo, São Paulo.

GUJARATI, D. Econometria Básica. 4 ed. Rio de Janeiro: Elsevier, 2006. 819 p.

GUTTENTAG, M. D. An Argument for Imposing Disclosure Requirements on Public Companies. Florida State University Law Review, n. 32, ago. 2004. Disponível em: <http:// www.law.fsu.edu/journals/lawreview/downloads/321/Guttentag.pdf $>$. Acesso em: 5 abr. 2012.

HENDRIKSEN, E. S. VAN BREDA, M. F. Teoria da contabilidade. 5 ed. São Paulo: Atlas, 1999. $550 \mathrm{p}$.

HOPE, O. Firm-level disclosures and the relative roles of culture and legal origin. Journal of International Financial Managerial and Accounting, v. 14, n. 3, p. 218-248, jan. 2003.

HUME, D. Investigação acerca do entendimento humano. São Paulo: Nova Cultural, 2004. $252 \mathrm{p}$.

IUDÍCIBUS, S. et al. Manual de Contabilidade Societária. São Paulo: Atlas, 2010. 792 p.

LIMA, E. M. Análise comparativa entre o índice disclosure e a importância atribuída por stakeholders a informações consideradas relevantes para fins de divulgação em Instituições de Ensino Superior Filantrópicas do Brasil: uma abordagem da Teoria da Divulgação. 2009. 200 f. Tese (Doutorado em Controladoria e Contabilidade) - Programa de Pós-Graduação em Controladoria e Contabilidade, Faculdade de Economia, Administração e Contabilidade da Universidade de São Paulo, São Paulo, 2009.

MACAGNAN, C. B. Evidenciação voluntária: fatores explicativos da extensão da informação sobre recursos intangíveis. Revista Contabilidade \& Finanças, USP, São Paulo, v. 20, n. 50, p. 46-61, mai./ago. 2009.

MENESES, A. F.; PONTE, V. M. R.; MAPURUNGA, P. V. R. Disclosure de Ativos Intangíveis em Empresas Brasileiras. In: Congresso ANPCONT, V, 2011. Vitória-ES. Anais... Vitória-ES: ANPCONT, 2011. CD-ROM.

MOURA, G. D. et al. Boas Práticas de Governança Corporativa e Evidenciação Obrigatória dos Ativos Intangíveis, 11, 2011. São Paulo. Anais eletrônicos... São Paulo: USP, 2011. Disponível em: <http://www.congressousp.fipecafi.org/artigos112011/507.pdf>. Acesso em: 9 mai. 2011.

NIYAMA, J. K.; GOMES, A. L. O. Contribuição ao aperfeiçoamento dos procedimentos de evidenciação contábil aplicáveis às demonstrações financeiras de bancos e instituições assemelhadas. In: Congresso Brasileiro de Contabilidade, 15, 1996. Brasília. Anais... Brasília: CFC, 1996. CD-ROM.

NUNES, J G.; TEIXEIRA, A. J. C.; NOSSA, V. Análise das Variáveis que influenciam a Adesão das Empresas ao índice Bovespa de Sustentabilidade In: EnANPAD, XXXIII, 2009. São Paulo. 
Anais... São Paulo: ANPAD, 2009. CD-ROM.

RAMSEY, J.B. Tests for Specification Errors in Classical Linear Least Squares Regression Analysis, Journal of the Royal Statistical Society, v. 31, n. 2, p. 350-371, 1969.

RECIO R., M. L. Los recursos intangibles: gestión y reconocimiento en las empresas españolas. Madrid: Instituto de Estudios Económicos, 2005, 264 p.

RÊGO, T. F. et al. Evidenciação do capital intelectual nas empresas do segmento de papel e celulose, registradas na BOVESPA. In: Congresso Brasileiro de Custos, 15, 2008, Curitiba. Anais... Curitiba: ABC, 2008. CD-ROM.

SILVEIRA, A. D. M.; BARROS, L. A. B. C.; FAMÁ, R. Determinantes do Nível de Governança Corporativa das Companhias Abertas brasileiras. In: Congresso SemeAd, 7, 2004, São Paulo. Anais... São Paulo: SemeAd, 2004. CD-ROM.

SCHMIDT, P.; SANTOS, J. L. Ativos Intangíveis nas Normas Internacionais - IASB. In: Convenção de Contabilidade do Rio Grande do Sul, 9, 2003, Gramado. Anais eletrônicos... Gramado/RS: Convenção de Contabilidade do Rio Grande do Sul, 2003. Disponível em: <http:// www.ccontabeis.com.br/conv/t01.pdf>. Acesso em: 9 mai. 2011.

STEWART, T. A. Capital Intelectual: a nova vantagem competitiva das empresas. 14 ed. Rio de Janeiro: Campus, 1998. 264 p.

VIEIRA, M. T. Evidenciação de informações de responsabilidade social na maior empresa em cada segmento da economia brasileira. 2006. 136 f. Dissertação (Mestrado em Ciências Contábeis) - Curso de Pós-Graduação em Ciências Contábeis, Universidade Regional de Blumenau, Blumenau.

WATTS, R. L.; ZIMMERMAN, J. L. Positive accounting theory: a ten year perspective. The Accounting Review, v. 65, n. 1, p. 131-156, Jan. 1990.

WATTS, R. L.; ZIMMERMAN, J. L. Towards a positive of the determination of accounting standards. The Accounting Review, v. 53, n. 1, p. 112-134, 1978.

ZANINI, F. A. M.; CALVO, L. C. Midiendo el Capital Intelectual de las empresas: propuesta de proxies. Revista BASE, São Leopoldo-RS, v. 3, n. 3, p. 297-310, set./ dez. 2006. 


\section{ENDEREÇO DOS AUTORES}

\section{Bruna Camargos Avelino}

Faculdade de Ciências Econômicas (UFMG)

Av. Antônio Carlos, 6627, Pampulha

31.270-010 - Belo Horizonte - MG - Brasil

\section{Laura Edith Taboada Pinheiro}

Faculdade de Ciências Econômicas (UFMG)

Av. Antônio Carlos, 6627, Pampulha

31.270-010 - Belo Horizonte - MG - Brasil

\section{Wagner Moura Lamounier}

Faculdade de Ciências Econômicas (UFMG)

Av. Antônio Carlos, 6627, sala 2036, Pampulha

31.270-010 - Belo Horizonte - MG - Brasil 